\title{
The Effects of Semantics in the Language Development of English as a Foreign Language (EFL) Learners
}

\author{
Fatimah Khalid Alsayed \\ Ministry of Education in Saudi Arabia \\ Dept. of Education, Lewis University \\ E-mail: fatimahalsyed@lewis.edu
}

Received: October 30, 2019 Accepted: December 20, 2019 Published: December 31, 2019

doi:10.5296/ijld.v9i4.15735 URL: https://doi.org/10.5296/ijld.v9i4.15735

\begin{abstract}
The study of Semantics is an important area of word meaning, references, senses, logic, and perlocutions and illocutions. That is, the study of Semantics increases students' understanding and awareness of word meaning, sentence relationships, and discourse and context. It also enables students to create and improve their Semantics maps which are webs of words visually display the meaning-based connections between a word or phrase and a set of related words or concepts. This paper is a product of effort that I make to implement some theoretically-sound strategies in planning and teaching a Semantic course for English Foreign language learners (EFL). The aim of this paper is to show that utilizing the mechanisms of meaning is vital to successful human communication. Alongside with that, lexical development will solidify students' understanding of language meaning and sense relations. The purpose of the course is to concentrate on teaching key terms in Semantics, Semantics Analysis of Writing Approach (SAW) and 'agent-action-goal with real-life action' technique and then employed the knowledge of these terms to improve students' vocabulary in the short-term, and their language proficiency in the long-term. Scaffolding the Semantics information with L2 vocabulary strategies is pivotal in language development. Implementing semantics strategies in an attempt to expose the relationship between teaching Semantics and improving ELLs' language skills.
\end{abstract}

Keywords: English as a foreign language, semantic analysis of writing, semantic mapping 


\section{Introduction}

The nature of this paper is to describe my academic and theoretical journey in teaching ENG 363: Semantics at Imam Muhammed Ibn Saud Islamic University in Saudi Arabia in Summer 2019. This reflection reports on my ENG 591 doctoral internship "The Effects of Semantics in the Language Development of English as a Foreign Language (EFL) Learners.” This report is a product of my effort to "implement some theoretically-sound strategies in planning and teaching a course" (Graduate Handbook 2015, 24). The ultimate goal of this course is to show that understanding the mechanisms of meaning is vital to successful human communication. Besides lexical development will solidify students' understanding of language meaning and sense relations. Therefore, this paper will answer this question: what kind of relationship is between teaching Semantics and improving ELLs' language skills? I designed this Semantics course to help my students to improve their English language skills utilizing the benefits of Semantics.

The paper reiterates the contextual background against which I designed a course on introduction to Semantics. Then I will discuss lexical development through understanding key concepts in Semantics with reference to relevant literature in the field. Then I reflect on why I chose ENG 363 as my internship course, how I designed the course, and why I arranged the readings in a particular way. I also explain the way I assessed student learning outcomes. For this, I designed the Second Vocabulary Journal Assignment, at the end of the semester, to seek students' perspectives toward the effectiveness of my teaching plan. I also talk about my struggles and challenges while teaching the course. Furthermore, I utilize technology in my class, namely Google Classroom, to facilitate and simplify creating, distributing, and grading assignments in a paperless way. Indeed, the primary purpose of using Google Classroom in my course is to streamline the process of sharing files between me and my students conveniently, especially in an environment where males and females are segregated in school. I conclude the essay by reflecting on how this internship project positively impacted my research agenda and doctoral dissertation plan.

\section{Statement of the Problem}

Teaching English in Saudi Arabia comes with several challenges when it comes to the use of pedagogy and materials. Some of the English language teachers in Saudi Arabia are relying on old-fashioned teaching methods such as the Grammar Translation Method while other teachers are unqualified to teach English due to their low English language proficiency. The revolution, as well as, the development of education in Saudi Arabia is renowned especially for implementing the English language in school, as a foreign language, and in scientific colleges as an English medium instruction (EMI). Although the Ministry of Education develops the curriculums and instructions of the English language in schools and universities all around Saudi Arabia, the level of achievement in teaching and learning English as a foreign language is far below (Mahib ur Rahman \& Alhaisoni, 2013). The low efficiency in teaching English is demonstrated by insufficient English language education (curriculum and instruction), unqualified teachers teaching in schools without evaluation/assessment from the Ministry of Education, limited English resources in schools and universities, and a few teaching 
developmental workshops for English teachers. In addition to the low efficiency in teaching English, students' English language proficiency is inadequate to study in the EMI context. Alshumaimeri (2003) proclaimed that "Teachers have pointed out that students leave the secondary stage without the ability to carry out a short conversation" (as cited in Mahib ur Rahman \& Alhaisoni, 2013, p. 114). Although students start learning English from the fourth grade until high school, one hour a day, five days a week, they achieve little in terms of language proficiency. Thus, the question that should be asked: why Saudi students' language development is insufficient and did not meet the expectations of the Ministry of Education. Fareh (2010) indicates some of the challenges of the EFL program in the Arab world:

a) Improperly trained teachers or inadequate teaching methodology.

b) Teacher-centered rather than learner-centered activities.

c) Students' aptitude, initial preparedness and motivation: School and university teachers often complain of the low proficiency of their students. They also claim that students are not motivated to learn.

d) Compartmentalization (Note 1) vs. whole language approach.

e) Lack of emphasis on developing skills- the emphasis is rather on rote learning.

f) Textbooks and teaching materials that are out-of-context or unrelated to the local culture.

g) Ineffective assessment methods.

h) Limited exposure to English contents (p.3601-3).

Similarly, it will be unjust to blame one particular issue, like the use of textbooks or students' motivations for the unsatisfactory result of English language learning in the Saudi Arabian context. There are a lot of other factors which also can be responsible for the low level of English proficiency such as; a) unclarity in the English language curriculum's aims and objectives; b) inadequacy in selecting appropriate English textbooks and materials; c) teachers' qualification and development; and d) students' exposure to the English language (Mahib ur Rahman \& Alhaisoni, 2013, p.115-6).

According to IELTS.org test-taker performance in the 2017 chart, in addition to my own learning and teaching experience of the English language in an EFL context, Saudi Arabia, and English-speaking contexts such as Britain, Canada, and United States, demonstrate that writing and reading are considered the most difficult language skills. After a brief description of the English language achievement in Saudi Arabia, why is the study of Semantics for teachers and students in the English as a second language (ESL)/EFL classroom important? What kind of relationship is between teaching Semantics and improving ELLs' skills in Saudi context? The study of Semantics is an important area of words meaning, references, senses, logic, and perlocutions and illocutions. That is, the study of Semantics increases students' understanding and awareness of word meaning, sentence relationships, and discourse and context etc. In fact, Semantics is the key to unlock understanding the language. In order for us to comprehend and 
communicate in a second language, we must understand the 1) surface and deep meaning of words; 2) synonyms and antonyms; and 3) learning strategies to support us in word retrieval during written and oral communication. Choosing the right words (or failure to) can have serious social, professional, and academic implications when it comes to communication in a second language, especially in written discourse.

\section{The Study}

Current studies have begun to simultaneously evaluate the importance of both Semantics and syntactic concepts in the process of language production (e.g., Cuza, Guijarro-Fuentes, Pires, \& Rothman, 2013; Gil \& Marsden, 2010; Han \& Liu, 2013; Ko, Perovic, Ionin, \& Wexler, 2008). For example, Beyersdorfer and Schauer (1989), among others, describes the relationship between teaching Semantics and improving writing skills. They implement the Semantics Analysis of Writing Approach (SAW) to enable students to expand and increase their word knowledge through analyzing English lexical synonyms, antonyms, homonyms, collocations, and connotations. They claim that the benefits of Semantics Analysis of Writing approach are the following: Firstly, it elaborates the student's schema of known vocabulary through small and large group discussions. Secondly, it facilitates the assimilation of new vocabulary into an established background at a deep level of processing. Thirdly, it provides a structure for students to correlate story events with elements of an expanded definition. Finally, it provides an organizational method for the supporting evidence used during writing.

In addition to SAW, Semantics can also enhance the student's ability to learn vocabulary effectively and then employ this knowledge in the social/interactional context appropriately. Folse (2004) emphasizes the importance of learning and implementing the acquired vocabulary of the second language profoundly related to how ESL/EFL teachers design and tailor their lessons to students' needs. In his book titled "Vocabulary Myths: Applying Second Language Research to Classroom Teaching", he mentions three important recommendations for language teachers to utilize a vocabulary list effectively; first, "Don't hesitate to use vocabulary lists." Second, "Don't rely only on word lists". Last, "Include your students' likes and dislikes as well as their classroom expectations in your teaching" (p.44-45). In other words, teachers need to design learning vocabulary activities to be more interactive, motivating, interesting to students, and more importantly, get in students involved and active. Also, teachers are required to diversify their teaching methods to fulfill students' needs and to consider the individual differences among them. English teachers in Saudi Arabia should stop applying the Students-passive-role strategy in the class. Indeed, students being passive in the classroom which commonly happens in Saudi Arabia especially in the English class is dated and urgently needs to be updated.

One of the challenges we have as English language teachers is how to teach that elusive connection between form and content or more specifically, between the ideas our students are trying to express and the sentences with which they choose to express those ideas. So, can knowledge of Semantics theories, such as Agent-Action-Goal with Real-Life Action, or Old Information then New Information Techniques benefit students as they attempt to express their ideas in writing? Semantics theorists provide cues for us. They see the structure of language 
rising out of the ideas we express; they, therefore, analyze sentences not as syntactic units "generated" out of an innate deep structure, but as syntactic units produced by the ideas that motivate discourse (Holloway, 1981).

Holloway (1981) argues that we have a valuable terminology by which to link the grammar of our sentences with the actual (or "real-world") actions they describe (p.206). He provides an example of how to utilize 'agent-action-goal with real-life action technique when a student writes a sentence like the following:

There was a misunderstanding on the part of the committee in regard to the basic problems that were involved in the investigation of the oil companies.

The teacher can ask the student such questions as, "Who or what is the real-life agent in this sentence?" If the student answers "committee," he or she has identified a key component of the Semantics structure of the sentence that will help him/her rebuild the sentence. What "action" did the committee perform? This might give the students some pause, but upon re-examining the sentence, they would probably come up with "not understanding" or "misunderstanding." You can probably ask the students to rebuild from there:
(agent)
(action)
(goal)
(agent)
(action)

The committee misunderstood the problems involved when they investigated the oil companies.

The advantage of this approach, as Holloway states, is to link Agent-Action-Goal with Real-Life Action to reduce the error of subject-verb agreement and pronoun reference (Holloway, 1981, p.206). However, in my teaching, I experienced this strategy when I explained Unit 20 titled "Participant Roles" in the required textbook "Semantics a coursebook", and I encountered this outcome. On the one hand, students who understood what agents and actions mean were able to take advantage of this technique. On the other hand, students who could not differentiate between agent and action due to lack of English proficiency were unable to implement this method successfully, hence failed in understanding the meaning of the sentence.

Schenck and Choi (2015), who studied English pedagogy in the South Korean context, state that EFL contexts require pedagogical and curricular reforms that foster the development of writing composition for Semantics and pragmatic purposes. Extensive instruction via traditional or dated EFL methodologies such as the Grammar-Translation Method or Audio-Lingual Method has presented challenges (Schenck \& Choi, 2015; Lee, 2014). Overemphasis of syntax, as well as extensive rote memorization of vocabulary, hinders understanding of top-down processes related to discourse and pragmatics. Schenck and Choi (2015) present an illustrative example of how some Korean EFL universities understand only the surface meaning because of the overemphasis on syntax. They provided a revealing example in their work which was a dialogue between South Korean and American students:

American: I'm so happy that you made these cookies!

Korean: Then you should say thank you! 
American: I thought I just did.

Misunderstandings such as these may be expected in the educational context that primarily emphasizes grammar at the expense of pragmatic and Semantics concepts. More examples are discussed in other studies that explain extensive Semantics and pragmatic failures among EFL students in terms of Semantics and pragmatics practice (Zheng \& Huang, 2010). Because Semantics and pragmatic downfalls may create a significant barrier and obstacles to communicate effectively in oral and written ways, more innovative and effective pedagogical techniques are needed in teaching the English language in EFL contexts.

I tried another semantic strategy with my students in this course while I was explaining Unit 10 "Sense Relations (1) Identity and Similarity of Sense." The strategy is known as 'Semantics Mapping'. This effective Semantics theory is what Barcroft (2004, p. 200) defines as "the increased evaluation of an item with regard to its meaning". Semantics mapping can be used as a tool for discovering the conceptual relationship between vocabulary items. Semantics elaboration seems to enhance word learning and retention, through a learning phase called integration (Shostak, 2003). It is believed that this will lead to deeper learning and thus longer retention of the learned words. Barcroft (2004) argues that Semantics elaboration of lexical items enhances their memory retention considerably among L2 learners. In short, Holloway, Barcroft, Shostak, and other scholars affirm that Semantics theories help students to improve their language proficiency. These theories will help students to assess and edit their sentences according to the English language norms and discourse. These theories enable students to write effective essays instead of good essays. Peer-review activities are useful to familiarize students with critical thinking (what is agent, action, goals of the sentences). I argue that Semantics could improve students' language proficiency in some way; however, according to my limited -one academic semester- teaching experience shows that conveying the intended ideas to a particular audience is much more important than using correct grammar structures especially in spoken communications. This is what Folse (2004) argues for in his book "Vocabulary Myths: Applying Second Language Research to Classroom Teaching”.

\subsection{The context: ENG 363: Semantics}

All our work, our whole life is a matter of Semantics, because words are the tools with which we work, the material out of which laws are made, out of which the constitution was written. Everything depends on our understanding of them (Felix Frankfurter).

In my internship course Semantics ENG 363 (Summer 2019) at Imam Muhammed bin Saud University, I taught 14 Saudi female students majoring in English. All of them were juniors who speak Arabic as a native language and English as a foreign language. Their English language proficiency, based on my assessment of their performance during the whole class period, was between 4 to 5.5 ILETS score which means limited to modest users. I implemented in teaching this course Content and Language Integrated Learning (CLIL) pedagogy, which is the dominant methodology of the EMI context. Based on the first class's communication, the majority of my students will become English language teachers, and a few of them will be writers or translators. They took ENG 363: Semantics because it is a mandatory course required for their degree. 
I focused on teaching key terms in Semantics and then employed the knowledge of these terms to improve students' vocabulary in the short-term, and their language proficiency in the long-term. Scaffolding the Semantics information with L2 vocabulary strategies is a significant reason to choose ENG 363. In addition, this course helped me to improve students' English language proficiency by studying Semantics. More accurately, students were exposed, for the first time, to the following Semantic concepts; reference and sense, referring expression, universe of discourse, deixis and definiteness, prototypes and stereotypes, meaning postulates, properties of predicates, derivation, participant roles, etc. In ENG 363, we discussed interpersonal and non-literal meaning. Students realized during this course how speech act through perlocutions and illocutions expressions. Knowing that will develop students' linguistic cognition, as Barcroft (2004) argues that Semantic elaboration of lexical items could enhance students' memory retention considerably. Therefore, students could produce more powerful texts and speech than those who do not study Semantics.

Furthermore, my students and I explored, in this course, the cognitive faculties that enable people to interpret and utilize language in context appropriately. In this exploration, it was required to look closely and critically at the study of meanings and how the meaning(s) could play different roles; consequently, meaning could be altered according to the context(s). We also delved into the structure of Semantics representations - a taste of logic, and how meanings change - metaphor and other tropes, Grammaticalization - how content words can be Semantically bleached and come to be function words, how context shapes meaning. In brief, the theories fall into two general intersecting categories: those theories that ask what kinds of categories words and constructions denote (Semantics theories) and those theories that ask how linguistic form is related to a conversational context (pragmatic theories). I focused more on the first part, Semantics theories, to fulfill the course description requirements, as well as to resonate with the students' proficiency level and academic needs.

\subsection{Course Planning and Implementation}

The design of ENG 363: Semantics involved a number of back and forth steps on my part, especially in deciding the content for the condensed course, which lasted for seven weeks. Initially, I created the content selectively from two books and several related articles, yet I recall my experience when I was studying in the same institution between 2009-2014, and I find it difficult for students to buy two books and read several foreign language readings. After consultation with three professors, Dr. Seloni, Dr. Smith, and Dr. Mohammed, I decided to select only one book titled "Semantics a coursebook" for Hurford, Heasley, and Smith (2007). The advantages of this book are; 1- is an introductory coursebook about Semantics which resonate with the students' needs and language proficiency, 2- divides each lesson into steady sequences (Entry requirements, Entry test, Introduction, Definitions, Examples, Practices, Feedback, comments, summary, and finally study guide and exercises). Based on my experience in studying and teaching this book, I found that the Examples and Feedback demystify complicated Semantics terminologies and make them accessible to students and novice teachers.

In order to help my students to achieve the course objectives, I carefully selected the required 
textbook as the main source and sequenced its chapters in what ultimately appeared to be four different stages, in which the readings and activities of each stage built upon those of the preceding one. In the following section, I will describe the stages briefly.

\section{Stage One}

At the beginning of the semester, students were exposed to basic ideas in Semantics. It is basically about sentences, utterances, propositions, reference, and sense. Along with reading the required texts, students were required to write two responses before and after each class. Students were also taught what Theory of Semantics means, and then they discussed what speaker and sentence mean to facilitate an intelligible communication. We also discussed the notions of sense and reference and how they are central to the study of meaning.

\section{Stage Two}

After explaining the foundation and basics of Semantics. I started explaining the importance of Dictionary and Word Meaning. The dictionary is a central part of the description of any language. I explained the three kinds of information about words in every adequate dictionary: Phonological information, Grammatical information, and Semantics information. In addition, students were shown the interconnectedness of the definitions that exist in a language (in this context the English language). After explaining how to utilize a dictionary effectively, I asked the students to discuss in class what they have been learning so far which I name it (First Journal Activity). The purposes of that is; first, track students' uptake from Unit 1 and 5; second, motivate them and increase their daily vocabulary list and share the learning experience with each other (for the discussion questions, see Appendix A).

\section{Stage Three}

I designed the first quiz through Google Classroom without this I declare my failure to communicate effectively with my students in two main components: 1) Reading Responses, and 2) Vocabulary Journal. The time of the quiz was intended to be assigned before the midterm because I wanted my students to know how I created/composed questions, and design the test. The quiz was divided into two sections; four multiple-choice questions and two short essay questions, with 10 points. After that, I reviewed, with my students, three units, and I gave them a guideline for the midterm exam to decrease the chance of confusion and exam anxiety.

\section{Stage Four}

After accomplishing most of the required readings, and done with midterm exam (which is still a burden for Saudi students once they heard about the exam), students were fully prepared and ready for the final curve of this course (Presentation, $2^{\text {nd }}$ Vocabulary Journal, and the Final exam). We discussed the following Units; three "Reference and Sense" and six "Interpersonal and non-literal meaning" then students shared their $2^{\text {nd }}$ Vocabulary Journal in Google Classroom and in-class, too. After that, students consulted me with their presentation topics derived from the two major themes (Lexical Development in an EFL context) and (Implementing English Medium Instruction in Saudi school). 


\section{Principles of Learning \& Assessment of Student Learning Outcomes}

I believe that the learning process that occurs inside the classroom is not isolated from the outside factors, and circumstances willingly or unwillingly influence students' learning processes. These factors or principles are pivotal; thus, I, as a teacher, will take them into consideration before designing a lesson plan. The seven principles are (Note 2):

a) Students' antecedent knowledge can help or hinder learning.

b) How students organize knowledge influences how they learn and apply what they know.

c) Students' motivation determines, directs, and sustains what they do to learn.

d) Students must acquire component skills, practice integrating them, and know when to apply what they have learned.

e) Goal-directed practice coupled with targeted feedback enhances the quality of students' learning.

f) Students' current level of development interacts with the social, emotional, and intellectual climate of the course to impact learning.

g) To become self-directed learners, students must learn to monitor and adjust their approaches to learning.

\subsection{Long-Term Course Outcomes: Description of Cognitive Skills to Be Developed}

This course enables students to:

a) Develop critical thinking skills to analyze and synthesize the different Semantic characteristics within one's own language and other languages.

b) Demonstrate the skill of recognition and distinction of the different terms of modern Semantics.

c) Develop maturity and self-growth in learning about one's own language and other languages.

d) Solve entailment problems by applying the basic rules of entailment and presupposition.

e) Demonstrate the skill of independent critical thinking.

f) Identify types of antonyms.

g) Identify lexical relations between words and sentences.

h) Demonstrate differences between L1 (Arabic) and L2 (English) in constructing meaning and entailments.

In order to make sure that students achieve, if not all, most of these outcomes, I adopted a number of strategies in organizing the course assignments and reading responses. Firstly, I 
made sure they read the text by asking them to write one-page long reading responses before coming to classes. I asked them to write 6 reading responses over the Summer semester. This gave them some flexibility to choose which reading to select. I continuously had a good number of posts (ranging from 12-14 posts) for each class on Google Classroom. The fact that I also asked them to write after-class-response for two reasons; first, I wanted to track their learning uptake and make sure they understood the lessons because some students could not understand the lesson before class discussion. The second reason was to track my teaching method(s) and how I delivered the lessons to my students. In fact, I required before and after class responses because it was my first class in teaching Semantics, and I wanted to make sure that I delivered the teaching message clearly and accomplished the mission successfully.

Secondly, I knew that some students would find it difficult to write more than 6 reading responses because it is a new activity for all of them; So, to keep them focused on readings, I assigned two quizzes: one before the mid-term exam and one before the final exam. These quizzes along with the mid-term test required the students to study and read the readings more thoroughly and help them to engage with the major issues arising from the readings.

Thirdly, I wanted the students to assume some more control over the discussion of Semantics and lexical development. So, I made every student lead the discussion of a chapter collaboratively with three other peers, each student discussed a unit. In this way, there were a total of 14 students leading a presentation. I found this activity interesting and informative as students brought in their own personal experience more actively into the discussion session. Throughout the student-led sessions, I have kept on adding my ideas and clarifying any confusion the student discussions (especially underprepared ones) might create.

Finally, at the end of the semester, I assigned two assignments; Research Paper, an optional activity, and Presentation which was mandatory. In the Research Paper, students were required to write a 5-6-page research paper on a topic that they think is controversial, recent and interesting. The major goal of this assignment was to make them synthesize different resources using an academic citation style (APA or MLA), and guide them to familiarize typical academic papers. Possible general themes for this kind of paper were "how meaning is constructed in our brain to understand new vocabulary, how can we, as a language learner, benefits from Semantics to improve other language skills? What are the perspectives toward implementing English Medium Instruction in scientific Colleges in Saudi Arabia?" Because this assignment was optional and students' time was limited (Note 3), I received only one paper out of 14 students. The student who did the assignment tried to implement the semantics strategies in her essay; however, because of the time limit, she was unable to achieve all the strategies I taught in this course.

In contrast, I was thrilled with the students' performance in the Final Paper Presentation activity. They presented profound topics utilizing PowerPoint slides. Q/A sessions after each presentation was required to allow students sharing their thoughts about the presentation. My role was to provide students with oral and written feedback on their work.

Thus, reading responses, quizzes, a mid-term test, discussion leadership, Vocabulary Journal, and the final presentation let me know whether my students were getting the course message 
and were learning things I wanted them to learn. Three students, among other classmates, seemed to have understood the importance of learning Semantics in terms of lexical development and language intelligibility. They became more aware of the complexity of meanings; i.e. the meaning of lexeme, when it is isolated from a sentence, and then how the meaning could vary depending on the context of the utterance/sentence.

\section{Conclusion}

While teaching the course and after finishing, I found out a number of things that did not work or proved to be challenging for me:

1. Limited experience in teaching generally, as well as specialized course, Semantics, specifically created and extra pressure on me as an instructor. I realized that it was taking me more time than usual to prepare for in-class discussion and presentation of the idea.

2. Engage students in an in-class discussion was challenging because schools are gender-segregated in Saudi Arabia. I tried to diversify the in-class participation strategies to break the obstacles and involve them effectively, yet they still had a gender barrier that prevented them from participating conveniently; as a result, I had to lecture more. However, putting them in groups or in pairs and allowing some waiting time in between my question and their answers helped me out in most cases.

3. It was challenging to explain to my students the Reading Response Activity since they have never heard about it. Most of them took this activity as a summary while I clarified for them several times that the Reading Response is not only a summary. A summary is part of it but not all. I provided them with a sample to refer them to articles and academic resources to show them the components of Reading Response paper. Some of my students improved their response, others remain the same.

4. I updated the course plan and made the Research Paper Assignment optional for the essence of time. In fact, teaching this course in a sixteen-week semester allows more time for students to accomplish this assignment.

Overall, I felt like I successfully explained the relationship between studying Semantics and its impact on learners' lexical development among a group of pre-service teachers, which I hope will lead to some qualitative changes in their language development and future teaching. Students and I fully-recognized the complexity of meaning, and how a word, separately or jointed in a sentence, could imply several logical connotations. In fact, Semantics facilitates vocabulary learning and develops students' linguistic repertoire. Therefore, sending a clear message, communicating effectively, and understanding the purpose of the speech rely on how we understand the context of speech and select the appropriate expressions. Future studies that interested in discussing the relationship between semantics and improving students' language literacy should elaborate more on how semantics and pragmatics together facilitate or hinder the communication between ELLs and native speakers. Also, longitudinal research is needed especially in the EFL contexts to assess the effectiveness of teaching Semantics and pragmatics for ELLs. 


\section{Macrothink}

\section{References}

Al-Shumaimeri, Y. A. N. (2003). A study of classroom exposure to oral pedagogic tasks in relation to the motivation and performance of Saudi secondary learners of English in a context of potential curriculum reform (Unpublished Ph.D. Thesis, University of Leeds, Leeds).

Ambrose, S. A., Lovett, M., Bridges, M. W., DiPietro, M., \& Norman, M. K. (2010). How learning works: Seven research-based principles for smart teaching.

Barcroft, J. (2004). Second language vocabulary acquisition: A lexical input processing approach. Foreign Language Annals, 37(2), 200-208. https://doi.org/10.1111/j.1944-9720.2004.tb02193.x

Beyersdorfer, J. \& Schauer, D. (1898). Semantics analysis to writing connecting words, books, and writing. Journal of Reading, 32(6), 500-508.

Celce-Murcia, M., \& Yoo, I. W. (2014). Discourse-based grammar and the teaching of academic reading and writing in EFL contexts. English Teaching, 69(1), 3-21. https://doi.org/10.15858/engtea.69.1.201403.3

Cuza, A., Guijarro-Fuentes, P., Pires, A., \& Rothman, J. (2013). The syntax-Semantics of bare and definite plural subjects in the L2 Spanish of English natives. International Journal of Bilingualism, 17(5), 634-652. https://doi.org/10.1177/1367006911435594

Fareh, S. (2010). Challenges of teaching English in the Arab world: Why can't EFL programs deliver as expected? Procedia Social and Behavioral Sciences, 2, 3600-3604. https://doi.org/10.1016/j.sbspro.2010.03.559

Folse, K. S. (2004). Vocabulary myths: Applying second language research to classroom teaching. Ann Arbor: University of Michigan Press. https://doi.org/10.3998/mpub.23925

Gil, K. H., \& Marsden, H. (2010). Semantics before syntax: L2 knowledge of anyone by Korean speaking learners. In M. Iverson, J. Tiffany, I. Ivanov, J. Rothman, R. Slabakova, \& M. Tyzna (Eds.), Proceedings of the Mind-Context Divide Workshop (pp. 40-51). Somerville MA: Cascarilla Press.

Han, Z., \& Liu, Z. (2013). Input processing of Chinese by ab initio learners. Second Language Research, 29(2), 145-164. https://doi.org/10.1177/0267658313479359

Heller, M., Sari, P., \& Joan, P. (2017). Critical Sociolinguistic Research Methods: Studying Language Issues That Matter. New York and London: Routledge. https://doi.org/10.4324/9781315739656

Holloway, D. W. (1981). Semantics grammars: How they can help us teach writing. National Council of Teachers of English, 32(2), 205- 218. https://doi.org/10.2307/356694

Hurford, J. R., Heasley, B., \& Smith, M. B. (2007). Semantics a coursebook. New York: Cambridge University Press. https://doi.org/10.1017/CBO9780511841668 


\section{Macrothink}

International Journal of Learning and Development

ISSN 2164-4063 2019, Vol. 9, No. 4

Ko, H., Perovic, A., Ionin, T., \& Wexler, K. (2008). Semantics universals and variation in L2 article choice. Proceedings of the 9th Generative Approaches to Second Language Acquisition Conference (GASLA 9), 118-129.

Lee, I. (2014). Teachers' reflection on implementation of innovative feedback approaches in EFL writing. English Teaching, 69(1), 23-39. https://doi.org/10.15858/engtea.69.1.201403.23

Mahib ur Rahman, M., \& Alhaisoni, E. (2013). Teaching English in Saudi Arabia: Prospects and challenges. Academic Research International, 4(1), 112-118.

Schenck, A. D., \& Choi, W. (2015). Improving EFL writing through study of Semantics concepts in formulaic language. English Language Teaching, 8(1), 142-154. https://doi.org/10.5539/elt.v8n1p142

Shostak, J. (2003). The value of direct and systematic vocabulary instruction. Sadlier-Oxford Professional Development Series, 7, 1-11.

Test taker performance 2017. (2019). Retrieved from https://www.ielts.org/en-us/teaching-and-research/test-taker-performance.

Zheng, L., \& Huang, J. (2010). A study of Chinese EFL learners' pragmatic failure and the implications for college English teaching. Polyglossia, 18, 41-54.

\section{Appendix}

\section{Appendix 1. First Vocabulary Journal Activity}

Dear Students; discuss the following questions with your group member, then share them with the whole class.

\section{Section One: Your journey in collecting and memorizing the vocabulary}

1- How do you collect your vocabulary/lexis? and why?

2- How do you check the spelling and pronunciation of the new words? What are the tools that you utilize/use to improve your vocabulary?

3- How often do you review your vocabulary journal? and what are the strategies to keep them in the long-term memory?

4- What are the ways that you implement to put new words in contexts? what are the benefits of understanding new words from the context?

\section{Section Two: Possible ways to get benefits from your vocabulary list(s)}

1- How do you save your vocabulary? and how can you find them when you need a specific one?

2- What are the possible settings or situations that allow you to utilize your vocabulary here 


\section{Macrothink \\ International Journal of Learning and Development \\ ISSN 2164-4063 2019, Vol. 9, No. 4}

in Saudi Arabia?

3- Does your gender as a female hinder your ability to practice your new vocabulary in a setting like Saudi Arabia? how?

4- What are the advices and recommendations could you provide to your classmates and any English language learners to improve her/his vocabulary?

5- Does the context of learning play important roles to enrich your vocabulary? why?

Section Three: English-language-majored students \&amp; potential English language teachers

1- Does teaching vocabulary helpful in language development? how?

2- Would you agree with that learning vocabulary and making vocabulary lists is wasting of time and effort? Why?

3- How can you teach your students a new vocabulary? How can you explain the meaning especially if the word has abstract meaning such as love?

4- Would you think games, for instance, video games have a pivotal/important role in lexical development?

\section{Appendix 2. Second Vocabulary Journal Activity}

Both Arabic and English languages are acceptable

\section{Questions to Be Considered in your Trajectory}

Use your creativity to compose an interesting and informative story/trajectory about your language progress through studying ENG Semantics Course in Summer 2019.

\section{Section One: Semantics and its Contributions to the Language Development}

Q1: What have you learned so far from Semantics in terms of language and vocabulary development?

Q2: In your perspective, what are the purposes of learning Semantics? In other words, why did you take ENG 363 Semantics?

Q3: How can you utilize the knowledge of Semantics to improve your English language?

Q4: After learning some Semantics facts about human communication and meaning delivery, how would that change your style of communication? In other words, did you alter your communication manner(s) or etiquette after taking this course, if so how?

Q5: In your perspective, what is the most beneficial assignment/activity in this course? 


\section{Section Two: Being a student in ENG 363 in Summer 2019}

Q1: What is your first impression when you take ENG 363 Semantics class?

Q2: What are the pros/advantages of taking ENG 363?

Q3: What are the cons/disadvantages of taking ENG 363?

Q4: What do think about the teaching methodology (Content and Language Integrated Learning) (Note 4) that the instructor utilizes while he is teaching ENG 363 ?

Q5: What are your perspectives toward implementing English Medium Instruction (EMI) in teaching ENG 363 Semantics?

Q6: Do you think using EMI demystify the difficulties of understanding the terms and concepts in ENG 363 Semantics Course?

Q7: If you were your instructor would you implement English as a medium of instruction? In other words, would you apply English in your teaching, or would you apply Arabic (students' native language)?

Good luck! and Verily, I cannot wait to read your interesting trajectory.

\section{Appendix 3. Students' Samples of the $2^{\text {nd }}$ Vocabulary Journal:}

When I have joined the university, I started to learn English language because of my goal after secondary school to learn English to help me have a good job in the future. I learned many important subjects like grammar, phonetics, syntax and finally Semantics.

I learned Semantics course in this summer term 2019. This course helps me to know how to understand the meaning of words. Also, this course helps me to be able to differentiate between the sentences and the utterances. I have learned many terms of language that help me in my daily life and developed my vocabulary in the language. Moreover, I have learned many words with two meanings and when and how I can use these words easily. I have learned polysemy also which is the words which have multiple meanings and how I use it. I think if I can make correct sentence, it may useless without the meaning, so Semantics help me to understand and try to guess the meanings of the words.

The knowledge of Semantics improves my English language through learning me the difference between utterance which is the normal speech without using grammatical rules and the sentence which need using grammatical rules. Semantics course helps me to improve my communication with others through using full sentence or phrases or utterances.

The most beneficial activities are the presentation and the research. The presentation helps me to practice speaking skill in front of my classmates. The research helps me to know how to write the research paper with references. There are many advantages in her teaching Semantics course: First, she teaches us how to prepare the unit before lecture. Second, she gives us many tasks to get full marks. Third, when I ask my instructor by email any question, she replies immediately. The instructor uses modern methods like preparing the lectures and using our imagination in write a story about our Semantics course. I think using English 


\section{Macrothink}

International Journal of Learning and Development

ISSN 2164-4063 2019, Vol. 9, No. 4

Medium Instruction (EMI) demystify some difficulties of understanding the terms and concepts in Semantics course.

\section{Notes}

Note 1. Compartmentalization means to divide the language into segments where students find difficulties to understand and comprehend the purpose of the knowledge; therefore, they could not utilize the language effectively especially in social interactions.

Note 2. Inspired by Ambrose, Lovett, Bridges, Norman, and DiPietro, (2010, p.5-8).

Note 3. It was only seven-week-semester and all of my students take two or three courses alongside ENG 363. Their research experience is inadequate, and the resources are limited.

Note 4. To know more about this methodology please visit this website: https://www.english.com/blog/content-and-language-integrated-learning/

\section{Copyright Disclaimer}

Copyright for this article is retained by the author(s), with first publication rights granted to the journal.

This is an open-access article distributed under the terms and conditions of the Creative Commons Attribution license (http://creativecommons.org/licenses/by/4.0/). 